\title{
Chemical composition, palatability and physical characteristics of venison from farmed deer
}

\begin{abstract}
The quality of venison from farmed deer were evaluated based on chemical composition, palatability scores, W-B shear force, ultimate $\mathrm{pH}$, and color. The samples of venison were derived from javan rusa (Cervus timorensis russa), moluccan rusa (Cervus timorensis moluccensis), sambar (Cervus unicolor brookei), fallow (Dama dama) and imported red deer (Cervus elaphus). Moluccan rusa and red deer were fed grass. Javan rusa, sambar and fallow deer were fed concentrate. The venison obtained from grazing deer (grass-fed) gave higher moisture content $(75.3 \%)$ than concentrate-fed or confinement-raised deer $(74.4 \%)$ and imported venison $(70.62 \%)$. Fat content in venison shows some differences between muscles and species. The concentrate-fed animals had a higher $(\mathrm{P}<0.05)$ fat content in the venison than the grazing deer. Temperate deer (fallow and red deer) showed higher $(\mathrm{P}<0.05)$ fat content than tropical deer (rusa and sambar deer). Venison obtained from concentrate-fed deer showed normal ultimate $\mathrm{pH}$ values ( $\mathrm{pH}$ Oे6.0) and more reddish in color than grass-fed deer. The concentrate-fed venison produced slightly higher $(\mathrm{P}>0.05)$ palatability scores than grass-fed venison. Feeding regimens (grass-fed vs. concentrate-fed) significantly $(\mathrm{P}<0.05)$ influenced fat composition in the venison of farmed deer in this study.
\end{abstract}

Keyword: Chemical composition; Concentrate-fed; Farmed deer; Grass-fed; Palatability; Venison 